\title{
CICLO DE VIDA, SUCESSÃO E PROCESSO DE GOVERNANÇA EM UMA EMPRESA FAMILIAR: UM ESTUDO DE CASO NO GRUPO SECULUS
}

\author{
Vera L. Cançado ${ }^{\mathrm{i}}$ \\ vcancado@gmail.com
}

Fundação Pedro Leopoldo - Pedro Leopoldo, MG / Brasil

Juvêncio Braga de Lima

juvencio.lima@fumec.br

Fundação Mineira de Educação e Cultura - Belo Horizonte, MG / Brasil

Cristiana Fernandes de Muylder

cristiana.muylder@fumec.br

Fundação Mineira de Educação e Cultura - Belo Horizonte, MG / Brasil

Ricardo Brandão Castanheira

rbcastanheira@yahoo.com

Fundação Mineira de Educação e Cultura - Belo Horizonte, MG / Brasil

Recebido em 27/07/2011

Aprovado em 22/03/2012

Disponibilizado em 01/08/2013

Avaliado pelo sistema double blind review

Revista Eletrônica de Administração

Editor: Luís Felipe Nascimento

ISSN 1413-2311 (versão on-line)

Editada pela Escola de Administração da Universidade Federal do Rio Grande do Sul.

Periodicidade: Quadrimestral

Sistema requerido: Adobe Acrobat Reader.

\section{RESUMO}

O modelo tridimensional de desenvolvimento, baseado em três eixos distintos e complementares - propriedade, família e gestão/empresa -, permite a análise e a compreensão do ciclo de vida da organização e do seu processo de sucessão. Os desafios e soluções desse processo convergem para um conjunto de ações, configurado sob a forma de governança. Este artigo tem como objetivo analisar o ciclo de vida e o processo de sucessão e de governança do Grupo Seculus. Trata-se de um grupo empresarial familiar mineiro que se encontra em sua primeira geração e em processo de transição para a segunda geração, sendo, portanto, uma unidade de análise relevante para a proposta estabelecida. Foi realizado um estudo de caso descritivo, de caráter qualitativo, sendo coletados dados secundários em documentos da empresa e da família; e dados primários, por meio de entrevistas semiestruturadas com pessoas-chave da família e/ou empresa. Participaram das entrevistas membros da família proprietária, familiares não acionistas empregados e não empregados da empresa e gestores não pertencentes à família. Utilizou-se a estratégia de construção da explanação para a análise dos dados. Os resultados indicam que a empresa encontra-se no estágio de sociedade entre irmãos, de trabalho em conjunto e de expansão/formalização. Identificou-se que a condução do processo sucessório ao longo do tempo ocorreu de forma contingencial e não planejada. Concluiu-se que a prática da governança representou um caminho para equacionar conflitos

REAd I Porto Alegre - Edição 75 - N 2 - maio/agosto 2013 - p. 485-516 
Ciclo de vida, sucessão e processo de governança em uma empresa familiar: um estudo de caso no grupo Seculus

reais e potenciais vinculados à sucessão, sobretudo com respeito à profissionalização. Este estudo pode trazer uma contribuição para a academia, pois associa três temas essenciais à condução das empresas familiares: o desenvolvimento dos ciclos de vida, como ferramenta de gestão; a sucessão, requerendo planejamento e preparação prévios; e a governança, como possibilidade de tratamento dos conflitos inerentes ao processo. Constitui ainda um avanço na medida em que estabelece críticas ao modelo de Gersick et al. (1997), principalmente no que diz respeito à questão da profissionalização e de práticas de governança. Pôde-se concluir, portanto, que a condução da sucessão em empresas familiares envolve desafios relativos ao desenvolvimento de famílias, da empresa e da propriedade. Tais desafios são bem encaminhados quando passam pela criação de estruturas que permitem à família proprietária participar das soluções, equacionadas por práticas de governança.

Palavras-chave: Empresas familiares; Modelo tridimensional de desenvolvimento; Ciclo de vida; Sucessão; Governança.

\title{
LIFE CYCLE, SUCCESSION AND GOVERNANCE PROCESS IN A FAMILY ENTERPRISE: A CASE STUDY IN THE SECULUS GROUP
}

\begin{abstract}
The three-dimension development model, based on three different and complementary axes: - ownership, family and business/management-allows analyzing and understanding the organizational life cycle and succession process. The challenges and solutions of this process converge to a conjunction of actions, configured as governance. This paper aims to analyze the life cycle and the succession and governance process in the Seculus Group. This family business is an enterprise group in the State of Minas Gerais. They are at the first generation in a transition process to the second generation, being therefore a reliable analyze unit for this study propose. We realized a descriptive and qualitative case study. We collected secondary data from the enterprise and family documents; and primary data through semi-structured interviews with key members of the family and/or of the enterprise. We interviewed members of the owner-family, and also with no-bonds-owner family members, working or not in the enterprise, and other managers without relations to the family. We used the strategy of explanation building for the data analysis. The results showed that the enterprise is in the stage of Sibling Partnership, of Working Together and of Expansion/Formalization. It was acknowledged that the conduction of the succession process occurred along the time in a contingency way. It was not planned. We concluded that the governance was a way to solve real and potential conflicts about succession, especially about professionalization. This study may bring some contribution to the academic, because it associates three themes, all essentials to conduce family enterprises: the family business life cycles, as a management implement; and the succession, needing planning and previous preparation; and the governance, as a way to solve the conflicts inherent to the process. It also consists in an advance, the way it formulates criticism about the model of Gersick et al. (1997), especially on the question of professionalization and governance practices. We conclude, therefore, that the conduction of succession in family businesses involves challenges related to the development of families, enterprises and ownership. Those challenges can be well faced by governance practices, with the formation of structures that make possible owner-family to participate of the solutions.
\end{abstract}

REAd I Porto Alegre - Edição 75 - N² 2 - maio/agosto 2013 - p. 485-516 
Vera L. Cançado, Juvêncio Braga de Lima, Cristiana Fernandes de Muylder \& Ricardo Brandão Castanheira

Keywords: Family enterprises; Three-dimension developmental model; Life cycle; Succession; Governance.

\title{
CICLO DE VIDA, SUCESIÓN Y PROCESO DE GOBIERNABILIDAD EN UNA EMPRESA FAMILIAR: UNO ESTUDO DE CASO EN EL GRUPO SECULUS
}

\begin{abstract}
RESUMEN
El modelo tridimensional de desarrollo, con base en los tres ejes, distintos y complementarios- propiedad, familia y gestión / empresa- permite a analice y comprensión del ciclo de vida y del proceso de sucesión. Los desafíos y soluciones de este proceso convergen para un conjunto de acciones, configurado en la forma de gobernabilidad. Este articulo tiene como objetivo analizar el ciclo de vida y el proceso de sucesión e de gobernabilidad del Grupo Seculus. Se trata aquí de un grupo empresarial del Estado de Minas Gerais, encontrando-se en su primera generación y en proceso de transición para la segunda generación, siendo, por tanto, una unidad de analice relevante para la proposición colocada. Un estudio de caso descriptivo, con carácter cualitativo se realizó, con la colecta de dados secundarios en documentos de la familia y de la empresa, y dados primarios pela utilización de entrevistas semi-estructuradas con personas-llave de la familia y/o de la empresa. Participaran de estas entrevistas miembros de la familia propietaria, familiares non accionistas empleados o no empleados de la empresa, así también con gestores que no pertenecen á la familia. Se utilizó la estrategia de construcción de explicación para el análisis de datos. Los resultados indican que la empresa está en la fase de Sociedad entre hermanos, de Trabajo en conjunto y de Expansión/ Formalización. Identificó-se también que la conducción del proceso de sucesión al longo del tiempo hizo-se en forma de contingencia, y sin plano ninguno. Concluí-se que la practica de la gobernabilidad representa un camino para resolver conflictos reales y potenciales vinculados a la sucesión, sobremodo a respecto de la profesionalización. Este estudio puede traer una contribución para la academia, pues asocia tres temas esenciales a la conducción de empresas familiares: el desenvolvimiento de ciclos de vida, como herramienta de gestión y la sucesión, precisando de planeamiento y preparación previos, y la gobernabilidad, como posibilidad de tratamiento de los conflictos inherentes al proceso. También trata-se de un avanzo, en la medida que establece criticas al modelo de Gersick et al. (1997), principalmente a lo que dice respecto a la cuestión de la profesionalización y de las practicas de gobernabilidad. Pode luego concluir, por tanto, que la conducción de la sucesión en empresas familiares envuelve desafíos relativos al desenvolvimiento de familias, de la empresa y de la propiedad. Estos desafíos están bien encaminados cuando pasan pela creación de estructuras que permiten á la familia propietaria participar das soluciones, solucionadas por medio de practicas de gobernabilidad.
\end{abstract}

Palabras Clave: Empresas familiares; Modelo tridimensional de desarrollo; Ciclo de vida; Sucesión; Gobernabilidad.

\section{INTRODUÇÃO}

Empreendimentos de origem familiar constituem a base da economia capitalista mundial. Apesar de estatísticas e estimativas às vezes pouco confiáveis, nos Estados Unidos REAd I Porto Alegre - Edição 75 - N² 2 - maio/agosto 2013 - p. 485-516 
Ciclo de vida, sucessão e processo de governança em uma empresa familiar: um estudo de caso no grupo Seculus

os grupos familiares empregam $62 \%$ da força de trabalho e respondem por $64 \%$ do Produto Interno Bruto (PIB). Dados sobre empresas familiares na Europa indicam que, na Espanha, $70 \%$ das empresas são familiares, chegando esse índice, na Inglaterra, a 75\% e na Alemanha a $80 \%$ dos empreendimentos privados, o que corresponde a $66 \%$ do PIB nacional (LETHBRIDGE, 2005). No Brasil, de acordo com Leone (2005), as empresas familiares são responsáveis por aproximadamente $48 \%$ do PIB e por $60 \%$ dos empregos. A despeito da importância desse tipo de empreendimento, sua taxa de mortalidade é alta: uma empresa familiar padrão tem expectativa de vida em torno de 24 anos, sendo que $70 \%$ não alcançam a segunda geração e, para cada duas que atingem esse estágio, apenas uma sobrevive, segundo Cohn (1991).

Alguns autores, como Lank (2003) e Grzeszczeszyn e Machado (2009), destacam algumas fraquezas que podem contribuir para a mortalidade das empresas, como: jogos de poder, prevalecendo habilidade política ou o fato de ser da família em detrimento da capacidade; descapitalização - caixa da empresa misturado com finanças dos familiares; falta de sistemas de gestão: planejamento, apuração de custo e de outros procedimentos como contabilidade e orçamento; cultura familiar interferindo negativamente nos negócios e nas questões relacionadas à sucessão; inexistência de sucessor competente na família ou fora dela; e rivalidades familiares ou não aceitação do sucessor escolhido. Lank (2003) afirma que a sustentabilidade do negócio da empresa familiar depende da habilidade do planejamento do processo sucessório, focando-se tanto no sucessor quando no sucedido.

Esse planejamento relaciona-se à compreensão do ciclo de vida da empresa ao longo do tempo e de seu impacto nas decisões empresariais (COHN, 1991). Estudos sobre os ciclos de vida nas empresas familiares ganharam corpo especialmente a partir do trabalho de Gersick , Davis, Hampton e Lansberg (1997), voltado para a análise e descrição do desenvolvimento da empresa familiar. O resultado desse trabalho deu origem ao modelo tridimensional de desenvolvimento, baseado em três eixos distintos e complementares: propriedade, família e gestão/empresa. A análise da evolução das três dimensões ao longo do tempo permite a compreensão da dinâmica das relações entre os familiares e seus interesses quanto à gestão e à propriedade, indicando uma relação de interdependência entre os subsistemas do modelo (GERSICK et al., 1997). Para cada dimensão, os autores apresentam diferentes fases e para cada fase os desafios estratégicos a serem enfrentados no âmbito desse tipo de empresas. Tais desafios requerem criatividade, ações e decisões dos gestores e membros das famílias empresárias, que convergem para um amplo conjunto, configurado sob a forma de 
Vera L. Cançado, Juvêncio Braga de Lima, Cristiana Fernandes de Muylder \& Ricardo Brandão Castanheira

governança. A governança é peça importante no processo de profissionalização das empresas familiares (BERNHOEFT; GALLO, 2003; COSTA, 2003; SILVA JR; MUNIZ, 2006). Para Lank (2003, p. 98), governança é um "sistema de estruturas e processos para dirigir e controlar corporações e prestar contas a respeito delas".

Partindo dessas considerações, este artigo tem como objetivo analisar o ciclo de vida e os processos de sucessão e de governança no Grupo Seculus. Para tal, foi realizada pesquisa empírica nesse conceituado grupo empresarial familiar mineiro, reconhecido pela sua solidez e tradição, que atua há 49 anos nos mercados regional e nacional. Seu principal negócio é a fabricação e comercialização de relógios, mas também atua nos segmentos de construção, imobiliário, financeiro e de tecnologia da informação. Atualmente, encontra-se em sua primeira geração e em processo de transição para a segunda geração, sendo, portanto, uma unidade de análise relevante para a proposta estabelecida. Foi realizado um estudo de caso descritivo, de caráter qualitativo, sendo coletados dados secundários em documentos da empresa e da família e dados primários em entrevistas semiestruturadas com pessoas-chave da família e/ou empresa.

Este estudo pode trazer uma contribuição para a academia, na medida em que associa dois temas essenciais sobre o tema: ciclo de vida e processo de sucessão na empresa familiar, trazendo um caso empírico que ilustra tal associação. Pode preencher, ainda, importante lacuna, identificada a partir de um metaestudo de artigos publicados em anais de eventos da ANPAD no período de 1997-2007, realizado por Paiva, Oliveira e Melo (2008). As autoras listaram 83 artigos relacionados ao tema empresas familiares durante essa década, o que indica produção ainda incipiente na temática, apesar de estar ocorrendo aumento na quantidade de trabalhos publicados. Os resultados revelaram que 56,6\% de 47 artigos analisados mais profundamente abordam as empresas familiares como objeto central de análise, enquanto o restante trata como unidade de análise ou observação para outra temática. A análise da questão da sucessão predomina nesses estudos (31,3\% do total), enfatizando a importância do tema para a academia brasileira. Há de se ressaltar que não foram encontrados estudos sobre a governança em empresas familiares, o que também indica uma lacuna a ser preenchida. Portanto, a proposta deste trabalho evolui ao trazer a análise da governança como forma de equacionamento dos desafios inerentes à sucessão nas empresas familiares.

\section{REFERENCIAL TEÓRICO}

REAd I Porto Alegre - Edição 75 - N 2 - maio/agosto 2013 - p. 485-516 
Ciclo de vida, sucessão e processo de governança em uma empresa familiar: um estudo de caso no grupo Seculus

Os estudos sobre empresas familiares constituem fenômeno recente, cujo interesse vem crescendo rapidamente. Esse interesse reflete-se no aumento de publicações, bem como de pesquisas e de cursos formais sobre o tema, ainda que possa existir discussão se empresas familiares constituiriam um tema específico para os estudos acadêmicos (HOY; SHARMA, 2006). No Brasil, podem ser observados os primeiros estudos sobre empresas familiares no início da década de 1990, com trabalhos e publicações voltados para consultoria. A academia começou a se preocupar com o tema no final dessa mesma década e os estudos sobre empresas familiares começaram a ocupar cada vez mais espaço nos eventos científicos EnANPAD e EnEO -, segundo Borges, Lescura e Oliveira (2010), Grzybovski (2007) e Paiva, Oliveira e Melo (2008).

Esse campo de conhecimento ainda recente manifesta o seu estágio ainda embrionário de seus estudos, na falta de consenso sobre o conceito de empresa familiar, seja no contexto nacional, segundo Silva, Fisher e Davel (1999), ou internacional, conforme Astrachan, Klein e Smyrnios (2006). Definir o que é uma empresa familiar é um problema em pesquisas sobre o tema. Na tentativa de analisar o assunto, apresentam-se no Quadro 1 alguns conceitos:

Quadro 1 - Conceitos e critérios de empresa familiar, ordem cronológica

\begin{tabular}{|c|c|c|}
\hline AUTOR(ES) & CONCEITO & Foco \\
\hline Donnelley (1964) & $\begin{array}{l}\text { Uma empresa é considerada familiar quando tem se identificado com } \\
\text { pelo menos duas gerações com uma família e quando essa ligação tem } \\
\text { influenciado a política da companhia e os interesses da família. }\end{array}$ & $\begin{array}{l}\text { Duas gerações da } \\
\text { família; influencia } \\
\text { na empresa }\end{array}$ \\
\hline Barry (1975) & Quando é, na prática, controlada pelos membros de uma única família. & Controle familiar \\
\hline Dyer Jr. (1983) & $\begin{array}{l}\text { A empresa familiar é uma organização na qual as decisões em relação à } \\
\text { propriedade e/ ou gerenciamento são influenciadas pela ligação com } \\
\text { uma família ou famílias. }\end{array}$ & $\begin{array}{l}\text { Gerenciamento- } \\
\text { propriedade } \\
\text { familiar. }\end{array}$ \\
\hline Bernhoeft (1987) & $\begin{array}{l}\text { É aquela que possui sua origem e sua história vinculadas a uma família } \\
\text { ou que mantém membros da família na administração dos negócios. }\end{array}$ & $\begin{array}{l}\text { Família -história e } \\
\text { direção }\end{array}$ \\
\hline Lodi (1998) & $\begin{array}{l}\text { A empresa familiar deve possuir valores institucionais que se } \\
\text { identificam com um sobrenome de família ou com a figura do } \\
\text { fundador. }\end{array}$ & $\begin{array}{c}\text { Tradições e } \\
\text { valores familiares }\end{array}$ \\
\hline $\begin{array}{l}\text { Barnes e Hershon } \\
\text { (1994) }\end{array}$ & $\begin{array}{l}\text { A empresa familiar é uma propriedade controlada por um indivíduo ou } \\
\text { por membros da família. }\end{array}$ & Propriedade \\
\hline $\begin{array}{c}\text { Tagiuri e Davis } \\
\text { (1996) }\end{array}$ & $\begin{array}{l}\text { São empresas nas quais dois ou mais membros da família influenciam a } \\
\text { direção dos negócios por meio de laços de parentesco, papéis de } \\
\text { gerenciamento ou direito de propriedade. }\end{array}$ & $\begin{array}{l}\text { Família - gestão - } \\
\text { propriedade }\end{array}$ \\
\hline $\begin{array}{l}\text { Gersick et al. } \\
\quad(1997)\end{array}$ & $\begin{array}{l}\text { É aquela na qual ocorre a intersecção entre os subsistemas propriedade, } \\
\text { família e gestão. }\end{array}$ & $\begin{array}{l}\text { Propriedade - } \\
\text { família - gestão }\end{array}$ \\
\hline $\begin{array}{c}\text { Chua, Chrisman e } \\
\text { Sharma (1999) }\end{array}$ & $\begin{array}{l}\text { É aquela gerida com a intenção de moldar ou persuadir a visão do } \\
\text { controlador por meio da coalisão dominante e controle dos membros da } \\
\text { mesma família ou de um pequeno grupo de famílias. }\end{array}$ & $\begin{array}{l}\text { Controle por } \\
\text { membros da } \\
\text { família }\end{array}$ \\
\hline $\begin{array}{c}\text { Lanzana e Constanzi } \\
\text { (1999) }\end{array}$ & $\begin{array}{l}\text { Um ou mais membros de uma família exercem controle sobre a } \\
\text { empresa, por possuir a propriedade do capital. }\end{array}$ & $\begin{array}{l}\text { Propriedade } \\
\text { familiar. }\end{array}$ \\
\hline $\begin{array}{c}\text { Danes et al. } \\
(2002)\end{array}$ & $\begin{array}{l}\text { A transferência da autoridade familiar é fator preponderante para o } \\
\text { sucesso do negócio e está relacionada à natureza da socialização dos } \\
\text { processos entre as gerações. }\end{array}$ & $\begin{array}{c}\text { Autoridade } \\
\text { familiar - } \\
\text { sucessão }\end{array}$ \\
\hline Suehiro e & [...] propriedade e controle estão nas mãos de um grupo com laços de & Propriedade - \\
\hline
\end{tabular}

REAd I Porto Alegre - Edição 75 - N 2 - maio/agosto 2013 - p. 485-516 
Vera L. Cançado, Juvêncio Braga de Lima, Cristiana Fernandes de Muylder \& Ricardo Brandão Castanheira

\begin{tabular}{c|l|c}
\hline \hline Wailerdsak (2004) & parentesco, de sangue ou por casamento, ou seja, uma família. & família \\
\hline Brochauss (2004) & $\begin{array}{l}\text { A persistência de transferência de autoridade na gestão de empresas } \\
\text { familiares entre as gerações é uma característica que perdura por } \\
\text { muitos anos. }\end{array}$ & $\begin{array}{c}\text { Gerenciamento } \\
\text { influenciado pelo } \\
\text { fundador. }\end{array}$ \\
\hline Uhlaner (2006) & $\begin{array}{l}\text { Empresa que tem a maior parte da propriedade nas mãos de uma } \\
\text { família e na qual pelo menos dois membros da mesma família ou são } \\
\text { proprietários e/ou gerenciam a empresa juntos. }\end{array}$ & $\begin{array}{c}\text { Propriedade - } \\
\text { família - gestão }\end{array}$ \\
\hline $\begin{array}{c}\text { Grzybovski } \\
(2007)\end{array}$ & $\begin{array}{l}\text { A expressão familiar deixa implícito o envolvimento de membros da } \\
\text { família no cotidiano da empresa, seja como proprietário, seja como } \\
\text { diretor principal. }\end{array}$ & $\begin{array}{c}\text { Propriedade - } \\
\text { família }- \text { gestão. }\end{array}$ \\
\hline \hline
\end{tabular}

Fonte: Elaborado pelos autores a partir de Silva, Fisher e Davel (1999) e outros.

Conforme se observa no Quadro 1, a maioria dos autores condiciona a caracterização da empresa familiar à propriedade da empresa e/ou à influência da família. A partir da definição seminal de Donnelley, que identifica a empresa familiar com a existência de duas gerações de uma família no poder, as definições passam pelos dois círculos - propriedade e gestão, conceito desenvolvido por Tagiuri e Davis na década de 1980 - e chegam ao modelo dos três círculos de Gersick e outros, na década de 1990.

Para fins deste trabalho, a partir dos diversos conceitos, optou-se por operacionalizar a definição de empresa familiar como aquela na qual duas ou mais pessoas de uma mesma família (ou de várias famílias, em empresas multifamiliares) são proprietários/acionistas e/ou participam do gerenciamento do negócio. Adota-se, neste trabalho, o conceito de família proposto por Grzybovski e Lima (2004, p. 7): "grupo de pessoas ligadas por relações parentais estabelecidas tanto por laços genealógicos, biológicos, quanto sociais, como por ocasião de uniões de casais com filhos oriundos de outros casamentos".

Entre os modelos que tratam do ciclo de vida da empresa familiar, orientando-se para a interdependência entre as dimensões gestão, família e propriedade, podem ser destacados os estudos de McGivern (1989), Ward (1998), Lodi (1987) e Gersick et al. (1997).

O modelo de McGivern (1989) é um dos pioneiros sobre ciclos evolutivos na empresa familiar. Fundamenta-se, essencialmente, na adaptação das funções da direção aos ciclos vitais da empresa. $\mathrm{O}$ autor estabelece cinco estágios evolutivos, sendo associadas a cada uma dessas fases características desejáveis ao gestor da empresa. Assim, no estágio inicial do negócio, são esperadas características relacionadas à inovação e capacidade de criação. $\mathrm{Na}$ fase de desenvolvimento, as características relacionadas a empreendedorismo e capacidade de execução tornam-se essenciais. Na maturidade, o gestor deve atuar como administrador, enquanto que na decadência é preciso agir como reorganizador e patrocinador do processo de transferência de poder.

Ward (1998) ressalta as forças que atuam sobre o desenvolvimento da empresa familiar ao longo do tempo, tais como: a natureza do negócio e da organização, a motivação REAd I Porto Alegre - Edição 75 - N 2 - maio/agosto 2013 - p. 485-516 
Ciclo de vida, sucessão e processo de governança em uma empresa familiar: um estudo de caso no grupo Seculus

do proprietário diretor bem como as expectativas econômicas e objetivos da família com o empreendimento. $\mathrm{O}$ autor fundamenta-se nesses fatores para propor um modelo de ciclo de vida constituído por três etapas: inicial, intermediária e avançada.

Um paralelo é estabelecido por Lodi (1987) entre o conceito de ciclo de vida do produto e de ciclo de vida da empresa familiar. Essa evolução relaciona-se com a própria biografia do fundador, tendo como pano de fundo a crença popular do pai rico, filho nobre e neto pobre. Assim, ele propõe o desenvolvimento da empresa familiar em quatro fases: fundação, crescimento, apogeu e declínio.

Gersick et al. (1997), por sua vez, defendem a evolução da empresa familiar em três eixos - propriedade, família, gestão/empresa. Os autores elaboraram o modelo tridimensional de desenvolvimento, resumido no Quadro 2. Considera-se que esses eixos são independentes e possuem sua própria dimensão de desenvolvimento (DAVEL; SILVA; FISCHER, 2000).

Quadro 2 - Principais características dos estágios de desenvolvimento da empresa familiar

\begin{tabular}{|c|c|c|}
\hline Dimensão & $\begin{array}{c}\text { Estágio de } \\
\text { desenvolvimento }\end{array}$ & Principais características do estágio \\
\hline \multirow{3}{*}{ Propriedade } & Proprietário controlador & Controle centralizado. \\
\hline & Sociedade entre irmãos & $\begin{array}{l}\text { O controle da empresa é efetivo na geração dos irmãos, estando } \\
\text { dois ou mais irmãos no controle acionário. }\end{array}$ \\
\hline & Consórcio de primos & $\begin{array}{l}\text { Muitos primos são acionistas e há mistura de sócios funcionários e } \\
\text { não funcionários. }\end{array}$ \\
\hline \multirow{4}{*}{ Família } & $\begin{array}{l}\text { Jovem família } \\
\text { empresária }\end{array}$ & $\begin{array}{l}\text { Geração adulta abaixo de } 40 \text { anos e filhos, se houver, abaixo de } 18 \\
\text { anos. }\end{array}$ \\
\hline & Entrada na empresa & $\begin{array}{l}\text { A geração mais velha entre } 35 \text { e } 55 \text { anos e a geração mais jovem } \\
\text { entre a adolescência e os } 30 \text { anos. }\end{array}$ \\
\hline & Trabalho conjunto & $\begin{array}{l}\text { Geração mais antiga entre } 50 \text { e } 65 \text { anos e a geração mais jovem } \\
\text { entre } 20 \text { e } 45 \text { anos. }\end{array}$ \\
\hline & Passagem do bastão & Geração mais velha com 60 anos ou mais. \\
\hline \multirow{3}{*}{ Empresa } & Início & $\begin{array}{l}\text { Estrutura organizacional informal, com a presença do proprietário- } \\
\text { gerente no centro. Geralmente desenvolve um produto. }\end{array}$ \\
\hline & Expansão/ formalização & $\begin{array}{l}\text { A estrutura fica cada vez mais funcional e desenvolvem-se produtos } \\
\text { ou linhas de negócios múltiplos. }\end{array}$ \\
\hline & Maturidade & $\begin{array}{l}\text { As rotinas organizacionais estão bem estabelecidas, com a estrutura } \\
\text { favorecendo a estabilidade e dirigida pela alta gerência. Base de } \\
\text { clientes estável ou com modesto crescimento. }\end{array}$ \\
\hline
\end{tabular}

Fonte: Gersick et al. (1997).

Pode-se assumir, portanto, que empresas familiares equivalentes em porte, estrutura, segmento de mercado e tempo de fundação venham a ter diferentes combinações de estágios de desenvolvimento, considerando que cada eixo, em cada caso, pode evoluir de forma independente, em face do histórico peculiar de cada empresa ou das mudanças que sofrem. Em qualquer estágio de desenvolvimento em que a empresa se encontre, Gersick et al. (1997) afirmam que a sucessão é o ato mais importante na empresa familiar.

REAd I Porto Alegre - Edição 75 - Nº 2 - maio/agosto 2013 - p. 485-516 
Vera L. Cançado, Juvêncio Braga de Lima, Cristiana Fernandes de Muylder \& Ricardo Brandão Castanheira

A sucessão em empresas familiares é, provavelmente, um dos temas mais estudados e pesquisados por especialistas nesse tipo de empreendimento. $\mathrm{O}$ interesse crescente por essa questão pode ser atribuído a diversos fatores. Entre eles, destaca-se o fato de que o sucesso ou o fracasso desse processo pode viabilizar ou comprometer definitivamente a continuidade do negócio. Pesquisadores observam que apenas reduzido percentual das empresas familiares sobrevive à transição da segunda geração (DAVIS; HAVERSTON, 1998; HANDLER, 1990; 1992; WARD, 2004). Casillas, Vázquez e Díaz (2007) relatam que estudo realizado na Europa indica que boa parte das empresas familiares é extinta após a segunda ou terceira geração, em função de um processo sucessório malplanejado. Ricca (2007) salienta que em várias empresas familiares os herdeiros sentem-se candidatos naturais a assumir o comando dos negócios, como se para isso nenhuma preparação prévia fosse necessária.

Boa parte do fracasso da não continuidade dos negócios familiares se deve ao entendimento errôneo de que sucessão é um evento isolado, cuja finalidade restringe-se à simples transferência de poder. Lank (2003, p. 72) advoga que "[...] a sucessão na gestão dos negócios deve ser tomada como uma série formal e planejada de atividades ao longo do tempo, de modo a criar um conjunto de talentos a partir do qual a decisão final de escolha do sucessor será feita quando o momento chegar”. Bernhoeft (1987) defende que a sucessão deve ser encarada como um processo que pressupõe a definição de atividades programadas e temporais, bem como a delimitação clara de papéis para as diferentes partes envolvidas.

Lodi (1987) confirma e acrescenta a essa argumentação que a sucessão é um processo que deve ser planejado com antecedência, ainda quando os filhos estão pequenos. Nesse sentido, o autor enumera algumas estratégias para se trilhar o caminho da infância até a transferência: formação de base dos sucessores, também chamada de berço; o plano de desenvolvimento; e medidas de caráter organizacional e jurídico. Na fase denominada berço, o caráter da família tem papel preponderante tanto na definição da vocação como na missão de promover o comprometimento dos filhos para assumir o negócio familiar. Além disso, o autor defende a importância da educação formal, por meio de boa formação universitária, bem como preparação prévia, por meio da atuação profissional fora da empresa familiar. No plano de desenvolvimento dos sucessores, Lodi (1987) propõe que a preparação deva se concentrar no conhecimento do negócio; na educação continuada; na formação do jovem casal; na vivência social (exemplos de ética e sucesso profissional); no desenvolvimento cultural; e na educação política. Na etapa seguinte, sugere modificações estruturais na empresa como forma de viabilizar a carreira do sucessor, tais como a criação de uma holding para controle do 
Ciclo de vida, sucessão e processo de governança em uma empresa familiar: um estudo de caso no grupo Seculus

grupo, transferência de ações e estabelecimento de consenso entre os acionistas, como forma de pavimentar o caminho para a sucessão.

É essencial planejar a sucessão por meio de definição prévia do perfil para que o sucessor possa fazer frente aos desafios da liderança empresarial (AMENDOLARA, 2005). A autora descreve, ainda, que o desenho desse perfil deva ensejar um processo de capacitação ao longo do tempo. Casillas, Vásquez e Diaz (2007) sugerem iniciar o planejamento com pelo menos 15 anos de antecedência em relação à data de aposentadoria do sucedido.

Ao se planejar o processo de sucessão, Cohn (1991) alerta que se pode encontrar barreiras emocionais e psicológicas que impactam o círculo familiar e podem comprometer a transferência de liderança para os sucessores. Assim, para viabilizar o processo de sucessão, o autor sugere traçar metas, planejar sucessão e resolver os conflitos entre os eixos empresarial e familiar. As diferenças nos ciclos de vida entre as gerações da família levam divergências que precisam ser resolvidas, como forma de assegurar e equilibrar processo de sucessão.

Para Oliveira (1999), o processo sucessório na empresa familiar pode ser conduzido por meio de duas possibilidades: a sucessão familiar e a sucessão profissional. Na primeira, a transição é feita exclusivamente por membros da família, identificando como vantagens: continuidade do comando dos negócios e manutenção do processo decisório; e como desvantagens: eventuais disputas por poder e dificuldade em demitir o executivo sucessor. Em relação à sucessão profissional, Oliveira (1999) cita benefícios: facilidade para selecionar o executivo com perfil adequado e flexibilidade para mudança de executivos. Quanto às desvantagens dessa alternativa de sucessão, destaca: a possibilidade de incorporar um estilo de gestão que vá de encontro à sua maneira de trabalhar. Lank (2003) admite a viabilidade da sucessão profissional quando enfatiza que o sucessor ideal é o mais competente, não importando se é ou não membro da família.

Esses aspectos, muitas vezes, expressam-se nos desafios de solução de processos sucessórios, desafios tão mais importantes quanto a complexidade das famílias e dos negócios, elementos significativos a serem considerados (SANDIE et al., 2006). Essa complexidade, em si mesmo, já é um desafio, quando empresas familiares poderiam deixar uma situação típica de um modelo de controle para um modelo de mercado, passando de um número mais baixo de membros da família com controle e com grande atividade, para um número reduzido de membros da família com controle e a propriedade mais distribuída (ASTRACHAN et al., 2006). 
Vera L. Cançado, Juvêncio Braga de Lima, Cristiana Fernandes de Muylder \& Ricardo Brandão Castanheira

As diferentes questões associadas ao processo sucessório indicam a imbricação de aspectos relativos à sucessão patrimonial e gerencial. Os desafios estratégicos, relativos ao ciclo evolutivo, seja no âmbito da família, da empresa ou da propriedade, são objeto de gestão. E o mecanismo apropriado para tal gestão é a governança. Abordagens teóricas diversas sobre a governança corporativa permitem enfocar aspectos estruturais e processuais associados às mudanças estratégicas que ocorrem na sucessão (NORDVQIST; MELIN, 2002). De um lado, no tocante aos aspectos estruturais, proprietários e seus fóruns: conselhos de famílias, encontros familiares, conselhos diretores e a alta direção; de outro lado, quanto aos aspectos processuais, volta-se o foco para as relações de poder, interações entre diferentes atores, forças institucionais e padrões culturais. A governança se expressa pela criação de mecanismos tais como conselhos específicos para discussões e soluções desses problemas, nos três níveis de poder (família, empresa e propriedade), correspondendo ao Conselho de Família, ao Societário e ao de Administração.

O Conselho de Família pode ser entendido como um espaço destinado à discussão de questões relacionadas ao papel a ser exercido pela família diante do negócio, de acordo com Lank (2003). Já o Conselho de Administração, na visão de Vidigal (1996), tem por finalidade zelar para que a diretoria aja em consonância com os interesses dos acionistas. Faz-se necessário que os acionistas, reunidos no conselho próprio, definam claramente as funções desses conselheiros. A composição de cada um desses conselhos dependerá do porte da empresa, tamanho da família, número de herdeiros.

As argumentações apresentadas até o momento só fazem comprovar a necessidade de compreender a sucessão à luz do ciclo de vida da empresa ao longo do tempo. Desse modo, é necessário interpretar sua história e avaliar as decisões tomadas, além de identificar a empresa em cada uma das dimensões de desenvolvimento, incluindo seus desafios estratégicos. Diante disso, a identificação prévia da empresa em cada um dos ciclos de desenvolvimento propriedade, família e gestão/empresa - pode fornecer subsídios para melhor entender as relações entre o processo sucessório e o processo de governança na empresa familiar.

\section{METODOLOGIA}

A metodologia adotada nesta pesquisa foi o estudo de caso descritivo. Segundo Yin (2005), esse método é recomendado, uma vez que permite a caracterização e explicação do fenômeno em seu contexto. Neste estudo, o desenvolvimento dos ciclos de vida da empresa e 
Ciclo de vida, sucessão e processo de governança em uma empresa familiar: um estudo de caso no grupo Seculus

o processo de sucessão não podem ser desconsiderados do ambiente que os cerca, razão pela qual o estudo de caso revelou-se como a melhor estratégia. Ademais, a complexidade da teia social que caracteriza uma empresa familiar justifica a necessidade de adoção dessa metodologia. Adotou-se o estudo de caso descritivo, pois foram descritos, registrados, analisados e interpretados os fatos e as informações obtidas por meio de entrevistas e pesquisa documental (GIL, 2007).

A metodologia de pesquisa adotada foi qualitativa, que viabiliza a exploração de contradições e paradoxos, característicos dos dilemas vividos no ambiente das empresas familiares (COLLIS; HUSSEY, 2005).

Considerando-se o propósito desta pesquisa, optou-se por utilizar o modelo tridimensional de desenvolvimento da empresa familiar desenvolvido por Gersick et al. (1997), para fundamentar a coleta e análise dos dados relacionados ao ciclo de vida do Grupo Seculus. Essa unidade de análise selecionada para este estudo constitui um sólido grupo empresarial mineiro, fundado há 49 anos. É composto por oito empresas controladas por uma holding de capital privado nacional. Atua nos segmentos financeiro, imobiliário, tecnologia da informática (TI), indústria e comércio de relógios e conta atualmente com cerca de 570 empregados diretos. A empresa foi escolhida por apresentar as características necessárias ao desenvolvimento desta pesquisa: trata-se de uma empresa familiar, fundada como uma sociedade entre irmãos em 1960 (o que caracteriza a primeira geração), que se encontra em processo de transição para a segunda geração.

A unidade de observação foi escolhida com base na matriz do modelo dos três círculos de Gersick et al. (1997), em que a superposição dos três círculos faz surgir sete setores distintos. Foram realizadas 14 entrevistas, sendo os entrevistados identificados pelos nomes e escolhidos por representarem os setores resultantes da interseção dos três círculos:

- Setor 1: familiares não acionistas que não participam da gestão - Adriane Azevedo e Marcelo Azevedo.

- Setor 2: acionistas, não familiares, que não participam da gestão - não foram identificados proprietários fora do círculo familiar.

- Setor 3: gestores e empregados, não acionistas e não familiares - Sérgio Nader, diretor comercial da Seculus da Amazônia Ltda., e Antônio Diniz, assessor do presidente da holding.

- Setor 4: familiares acionistas que não participam da gestão - Rosângela Azevedo e Ílvio Azevedo.

REAd I Porto Alegre - Edição 75 - N² 2 - maio/agosto 2013 - p. 485-516 
Vera L. Cançado, Juvêncio Braga de Lima, Cristiana Fernandes de Muylder \& Ricardo Brandão Castanheira

- Setor 5: gestores acionistas, não familiares - não foram identificados gestores acionistas não pertencentes à família.

- Setor 6: familiares não acionistas que participam da gestão - Alexandre Azevedo, presidente da Seculus da Amazônia S/A, Lílian Azevedo, diretora do Capital Humano $(\mathrm{CH})$ Corporativo, e Roberto Azevedo, presidente da Pryme Systems.

- Setor 7: familiares, acionistas que participam da gestão - Artur Azevedo, presidente da holding, Márcio Azevedo, presidente da Seculus Empreendimentos e Participações S/A., Élcio Azevedo, presidente do Banco Semear, Jairo Azevedo, presidente do Conselho de Acionistas, e Ricardo Azevedo, membro do Conselho de Administração.

Neste estudo, o levantamento de dados foi efetuado por meio de entrevistas, tendo como referência um roteiro semiestruturado, com perguntas direcionadas para os diferentes públicos. Como complementações às entrevistas, foram utilizados dados secundários disponíveis na empresa, tais como informativos sobre a família, registros de dados históricos, acordo de acionistas, genograma e livros.

A técnica de análise de dados aplicada baseou-se na estratégia de construção da explanação, que tem por objetivo "analisar os dados do estudo de caso construindo uma explanação sobre o caso" (YIN, 2005, p. 140). De posse desses dados, coube aos pesquisadores separar os temas trabalhados em cada transcrição, tendo como referência as perguntas formuladas, categorizadas em ordem sequencial, nos três eixos da empresa familiar: propriedade, família e gestão e confrontando as informações com o referencial teórico, de maneira a explicar o fenômeno.

\section{FAMÍlIA, EMPRESA E PROPRIEDADE: CICLOS DE VIDA DO GRUPO SECULUS}

O dia 21 de abril de 1960 representou um marco na vida da família Azevedo, quando Jairo Azevedo e outros sete irmãos (Aguinaldo, Artur, Ílvio, Márcio, Élcio, Maria Augusta e Joaquim) formaram uma sociedade cujo foco era a comercialização de joias. Nessa reunião, forjou-se o lema que até hoje acompanha os irmãos fundadores: "Unidos, venceremos". Dois anos depois, em 1962, foi inaugurado o primeiro escritório de vendas de joias, em Belo Horizonte, que passou a ser o empreendimento predominante dos irmãos Azevedo. Em 12 de outubro de 1964, Jairo e seus irmãos inauguraram a Joalheria Ouvidor e, a partir de então, iniciaram as vendas de joias no atacado, o que deu novo impulso aos negócios. Os anos 
Ciclo de vida, sucessão e processo de governança em uma empresa familiar: um estudo de caso no grupo Seculus

subsequentes levaram à ampla diversificação dos negócios: produção própria de joias e de relógios; atuação no ramo da construção civil e no setor imobiliário; atividades no segmento financeiro - distribuidora de títulos e valores imobiliários, previdência privada, banco múltiplo e financeira; e atuação no segmento de tecnologia da informação.

Atualmente, o Grupo Seculus está estruturado em três segmentos distintos: setor de indústria e comércio; setor imobiliário; e setor financeiro e de serviços, tendo também constituído uma holding. O setor de indústria e comércio engloba a Seculus da Amazônia Indústria e Comércio S/A. e a Seculus Internacional S/A., empresa fundada em 2008, fruto da expansão do negócio de relógios para o mercado externo. No setor imobiliário, destacam-se a GranViver Urbanismo S/A., empresa voltada para a incorporação de loteamentos, a Seculus Empreendimentos e Participações S/A., que atua com venda e aluguel de imóveis, e a Seculus Construções, com foco no setor da construção civil. Já no setor financeiro, destacam-se o Banco Semear e a Pryme Systems, nome fantasia dado à Seculus Tecnologia. Embora a Pryme Systems atue no setor de tecnologia da informação, não foi criado um segmento específico para abrigá-la, na medida em que o seu volume de negócios não justificava tal opção. Tal atitude revela a preocupação do grupo em crescer de forma sustentável e direcionada, tentando evitar erros do passado, quando negócios foram abertos e fechados por falta de planejamento e de definição estratégica.

Essa situação atual representa uma evolução do grupo, iniciada desde 2002, quando Artur Azevedo, ao assumir a presidência da holding, iniciou um trabalho de reestruturação do grupo, fundamentado em três pilares: gestão, profissionalização e sucessão. Tal decisão marcou o início do processo de profissionalização e reformulação dos mecanismos de gestão.

Em 2003, com o auxílio de uma consultoria (Renato Bernhoeft), foi elaborado o Acordo de Acionistas, documento que objetivou estabelecer um conjunto de direitos e obrigações para herdeiros e acionistas, que tratou das relações, até então informais, e criou regras para entrada, transferência, promoção e saída nas empresas de sócios, herdeiros e cônjuges. A partir dessa fase, iniciou-se a discussão de como os herdeiros seriam capacitados. Dessa forma, dos 64 familiares da segunda geração que atuavam na empresa até 2002, apenas sete permaneceram. Esse processo de enxugamento ocorreu em curto espaço de tempo e, embora traumático, marcou o começo de uma nova mentalidade que, atualmente, representa a visão predominante dos acionistas: gestão por meio da meritocracia. É o que relata Élcio Azevedo ao referir-se à forma como o grupo passou a enxergar a entrada e permanência de familiares na gestão: “[...] consideramos hoje que a porta de entrada é muito estreita. A porta 
Vera L. Cançado, Juvêncio Braga de Lima, Cristiana Fernandes de Muylder \& Ricardo Brandão Castanheira

de saída já praticamente não existe mais. A gente considera que aqueles que aqui estão provavelmente serão consolidados dentro do grupo por competência, por resultados".

Essa visão é compartilhada por Roberto Azevedo, herdeiro e presidente da Pryme Systems, ao afirmar: "Hoje, a empresa está muito mais madura. A família ainda é muito importante, tem cargos estratégicos nas empresas do grupo, mas você vê um movimento para que a competência esteja sempre prevalecendo".

A revisão das estratégias empresariais promovida pelo Planejamento Estratégico resultou, em 2006, no fechamento do negócio de joias, 46 anos após o início desse empreendimento. Jairo Azevedo comenta por que essa decisão foi tomada:

Infelizmente, o ramo de joias chegou ao fundo do poço. Depois de alguns anos trabalhando no vermelho, meus irmãos julgaram que era hora de pararmos de perder dinheiro. O ramo foi muito bom enquanto durou. Teve sua época áurea. Tudo que realizamos foi proveniente, principalmente, desse ramo. Os ventos mudaram e precisávamos reconhecer isto.

Mais tarde, por volta de 2005, criou-se o Capital Humano (CH) Corporativo, setor responsável por elaborar e padronizar as políticas e práticas de recursos humanos em todas as empresas. Esse setor, atualmente, tem como prioridade a elaboração de diagnósticos voltados para aferir o perfil profissional e pessoal de todos os gestores das empresas, familiares ou não. Mais recentemente, em 2008, criou-se a Controladoria do Grupo, voltada para unificar dados e processos contábeis e financeiros.

Diante do exposto, percebe-se que o Grupo Seculus encontra-se no estágio de expansão/formalização, o que confirma a visão de Gersick et al. (1997) acerca do crescimento contínuo e desordenado que caracteriza esse estágio. O Grupo Seculus experimentou, de 1970 a 2006, intensa diversificação em suas atividades empresariais, fato que também corrobora a visão dos autores. Do mesmo modo, são percebidas inovações na estrutura e nos mecanismos de gestão das empresas, o que se comprova com a criação do $\mathrm{CH}$ e da Controladoria corporativos.

Em relação ao desenvolvimento da família, conforme a tipologia empregada, pode-se afirmar que essa empresa, criada por um grupo de irmãos, não seria o caso típico de jovem família empresária. Os irmãos Azevedo eram ainda muito jovens. Jairo, o líder do empreendimento, contava 21 anos. Todos eram solteiros e não possuíam filhos. Assim que os filhos se casavam, as relações familiares tornavam-se mais complexas. A esposa de Jairo ressentia-se do seu grande envolvimento com as atividades profissionais, sentindo que a dedicação dele era superior à dos demais irmãos. Jairo se contrapunha: - "Eu tentava explicar que nossa força [dos irmãos] estava exatamente em nossa união, que unidos seríamos fortes e 
Ciclo de vida, sucessão e processo de governança em uma empresa familiar: um estudo de caso no grupo Seculus

separados não seríamos nada, mas ela simplesmente não dava ouvidos às minhas explicações”. Essa situação culminou com a indisposição dela contra alguns dos irmãos de Jairo que, na época, residiam com o casal, mas fortaleceu a relação entre os irmãos, dando a tônica de um dos valores centrais dessa empresa familiar - o trabalho como uma das bases fundamentais para assegurar o sustento e a união da família.

Atualmente, considerando-se todos os familiares vivos que compõem a estrutura atual da família Azevedo, registram-se 10 membros na primeira geração, entre sócios e não sócios, 61 na segunda geração, 113 na terceira e quatro na quarta geração. Considerando-se apenas os sócios atuais, têm-se sete membros na primeira geração, 39 na segunda geração e 42 na terceira.

No Grupo Seculus, a entrada dos filhos nas empresas ocorreu naturalmente, sem planejamento prévio. Não havia regras de admissão a serem seguidas, o que dava a cada irmão fundador a liberdade de introduzir seus filhos no negócio da maneira como achavam mais conveniente. Artur Azevedo, ao comentar o fluxo de entrada de familiares no negócio, revela que, por vezes, se surpreendia com a presença crescente dos filhos nas empresas do grupo:

Quando eu assustava, trombava com um sobrinho [...] "Está trabalhando aí? Ah, que legal!" Trombava com outro, "ah que legal!” Depois, encontrava com meu filho... "Legal, tá trabalhando aí?" Aí um irmão meu dizia: “Ah, eu trouxe fulano, não vou deixar ele ficar em casa [...] tem de vir trabalhar".

Com a expansão dos negócios, intensificava-se a necessidade de contar com pessoas de confiança nos quadros das empresas. Em outra perspectiva, o próprio crescimento da família, ocorrido à proporção que os irmãos casavam e tinham filhos, forçou a entrada dos familiares. Essa entrada na empresa, muitas vezes, não se apresentava como uma opção dos filhos, mas sim como um caminho imposto pelo negócio ou pelos pais. Em confirmação a essa perspectiva, Lílian Azevedo, filha de Márcio Azevedo, relata a dificuldade que sentia em abraçar alguns dos desafios propostos pelo pai, mas, ao mesmo tempo, admitia a necessidade de servir ao empreendimento, mesmo que isso representasse um sacrifício para ela.

\footnotetext{
Por várias vezes, ao longo do tempo, eu ia para os lugares chorando. Pensava: "Vou ter que trabalhar nesse lugar, meu Deus, eu não acredito". E chorava semanas. Mas aí eu pensava assim: "Essa é a empresa da minha família, do meu pai. Eles precisam de mim lá”.
}

Assim, cargos e pequenos negócios foram criados para abrigar membros da segunda geração, assim como os seus cônjuges. É o que relata Élcio Azevedo: "Como nós tínhamos 
Vera L. Cançado, Juvêncio Braga de Lima, Cristiana Fernandes de Muylder \& Ricardo Brandão Castanheira

muita mão-de-obra na família, a nossa família é muito grande, então foi agregando muita gente da família nos negócios e principalmente no negócio principal, que eram joias”.

No início dos anos 1990, os vários herdeiros da segunda geração, já ocupando alguns cargos importantes na empresa, por iniciativa própria criaram o grupo de sucessores, cuja finalidade era trazer à tona a discussão sobre o futuro da empresa, passando necessariamente pelo planejamento do processo sucessório. Roberto Azevedo revela o momento em que procurou o tio, Jairo, para tratar do tema sucessão, na condição de representante do chamado grupo de sucessores:

Em 1994, fui conversar com o Sr. Jairo que a gente precisava fazer algum trabalho para a questão da sucessão. E aí ele disse: "O que você quer? Que eu me levante, saia da minha cadeira e você sente aqui?". Ele foi superdireto e, do jeito dele, disse: "Eu acho que a sucessão é natural, pronto." [...] Eu fui representando a segunda geração. A gente tinha alguns representantes de cada família. $\mathrm{Na}$ verdade, os filhos da primeira geração que trabalhavam [...].

A questão da sucessão, portanto, não estava em discussão, pois não havia uma ação planejada para viabilizar a passagem de bastão. É o que confirma Artur Azevedo, quando comenta que o crescimento da empresa não considerava a importância do processo sucessório: “[...] e conseguimos uma coisa daqui, outra dali, mas sem uma preocupação que amanhã iria ter uma sucessão. Ninguém estava pensando em sucessão".

Com o tempo, mais e mais familiares passaram a trabalhar nas empresas. Até por volta de 2002, havia um total aproximado de 64 familiares trabalhando no grupo, o que incluía filhos, cônjuges e cunhados. Prevalecia entre os acionistas a forte convicção de que a empresa deveria funcionar como uma fonte de renda e de emprego para os familiares. "Existia uma ideia de que no grupo caberia todo mundo e que nós queríamos realmente toda a família trabalhando. Depois, a gente chegou a uma conclusão diferente, quando nós iniciamos um processo de trabalho com a família” - comenta Márcio Azevedo.

Essa visão prevaleceu até a permanência de Jairo Azevedo na direção dos negócios. Em 2002, ele se afastou do controle e um dos irmãos, Artur Azevedo, assumiu a presidência da holding. Sob sua direção, foram estabelecidos critérios profissionais para a entrada e permanência de familiares nos quadros das empresas, o que culminou com a saída, em alguns casos espontânea e em outros induzida, de vários herdeiros que trabalhavam no grupo. Esse fato marcou o fim da visão até então predominante entre os acionistas de que os familiares deveriam ocupar seus lugares na empresa por questões meramente hereditárias.

Em 2003, com a implantação do acordo de acionistas, a entrada de familiares nas empresas passou a ser gerida por meio de critérios claros. Inicialmente, estabeleceu-se uma 
Ciclo de vida, sucessão e processo de governança em uma empresa familiar: um estudo de caso no grupo Seculus

restrição que impedia a entrada ou permanência de cônjuges de sócios ou herdeiros. Além disso, a admissão de sócios ou herdeiros ficava condicionada a premissas como: existência de vaga com atribuições definidas; comprovação de experiência externa profissional de pelo menos um ano; aprovação da admissão pelo Conselho de Administração, por meio de processo seletivo formal; e sujeição do admitido às políticas salariais e administrativas da empresa. Essa é a situação que perdura até hoje.

Historicamente, ocorreram três processos sucessórios no Grupo Seculus, sendo que em todos a estrutura de propriedade manteve-se intacta. O primeiro se deu por volta de 1998, quando Ricardo Azevedo, filho de Jairo, assumiu a presidência da Seculus Joias, uma unidade de negócios da Seculus da Amazônia até então liderada por Márcio Azevedo. Ricardo permaneceu na presidência por período de aproximadamente seis a sete anos, tendo se afastado do grupo por ocasião do fechamento da operação. Em 2002, Artur Azevedo ascendeu à presidência da holding, em substituição ao irmão Jairo. Com essa mudança, surgiu como decorrência natural o terceiro evento sucessório, quando Alexandre Azevedo assumiu a presidência da Seculus da Amazônia, em substituição a seu pai, Artur. Isso aconteceu naturalmente, já que a oportunidade surgiu e que os fundadores viram em Alexandre a pessoa certa para aquela função, pois já exercera anteriormente várias posições de liderança na hierarquia da empresa. Jairo Azevedo conta o momento em que Alexandre assumiu esse posto:

Com a minha saída da presidência da holding, Artur ocupou o meu lugar e o Alexandre assumiu a presidência da Seculus da Amazônia. Ele tem desempenhado muito bem sua função, tanto que hoje ocupamos o segundo lugar entre os fabricantes de relógios no Brasil. A capacidade do Alexandre é inquestionável.

Pode-se afirmar que o estágio "passagem de bastão" ainda não fora vivenciado plenamente no caso em estudo. Os eventos sucessórios relatados representam os únicos momentos em que a segunda geração ascendeu ao poder, sob a chancela de Jairo. Ainda assim, tais fatos foram motivados por aspectos contingenciais, e não como fruto de planejamento prévio. Diante dessa realidade, pode-se inferir que a transferência de poder da primeira para a segunda geração encontra-se revestida de incertezas. Por essa razão, há pensamentos distintos sobre como se dará a passagem de bastão na presidência da holding. Sobre essa questão, Márcio Azevedo comenta:

[...] eu diria que nós temos dois, talvez três com o perfil mais adequado. Agora, se um deles será escolhido é outra história. Nós achamos que os três ainda estão verdes. Ainda têm de adquirir mais experiência, mais vivência e mais conhecimento. Agora, à época da sucessão, eu digo com muita tranquilidade que eles estarão no processo. Se vão ser escolhidos, vai falar a competência mesmo.

REAd I Porto Alegre - Edição 75 - N² 2 - maio/agosto 2013 - p. 485-516 
Jairo Azevedo corrobora essa visão e comenta o estágio de profissionalização em que se encontram as empresas do grupo: "Eu acho que nós atingimos $40 \%$ de profissionalização. Faltam 60\%. Eu acho que nós já trabalhamos demais, principalmente na administração do Arthur, muito mais que na minha”. Na mesma direção, Élcio Azevedo descreve sua visão sobre a profissionalização no Grupo Seculus, enfatizando o ganho obtido nos últimos anos: "Esse é um processo que eu gostaria que estivesse um pouco mais avançado. Mas, como é um processo evolutivo, eu acho que estamos evoluindo bem. Agora, um pouco mais acelerado".

Por essa razão, Márcio não descarta a possibilidade de uma sucessão profissional, ou seja, por meio da contratação de um profissional de mercado, não pertencente à família: “Apesar de termos dois ou três com condições, eles também sabem que o processo será totalmente pela competência. Então, eles sabem que poderão estar subordinados a algum profissional externo". Sobre a possibilidade da sucessão profissional, Lílian Azevedo, responsável pelo $\mathrm{CH}$ Corporativo, faz comentários tendo em vista a necessidade de se identificar um sucessor cujo perfil se adapte à realidade e às necessidades do Grupo Seculus:

[...] é a nossa realidade agora uma pessoa de fora? Eu penso que não. Então, a gente vai ter que trabalhar com as pessoas que estão aqui dentro. Quem são as pessoas que estão aqui dentro? São só duas? Então, agora, tem que pegar o perfil que eu preciso e ver qual que está mais alinhado a ele.

Rosângela Azevedo, filha de Jairo Azevedo, acionista do grupo, entende que a sucessão profissional poderia descaracterizar a essência do grupo, tendo em vista que suas características confundem-se com os valores praticados na família:

\footnotetext{
Como acionista, sou bastante resistente à sucessão profissional. Se isso ocorrer, irão prevalecer apenas os números. Não tem mais aquela coisa de sentimento, de família, de "Unidos, venceremos". Nesse caso, estariam visando apenas ao mercado, [...] o nome Seculus virará uma grife.
}

Em análise final, pôde-se observar também que não havia, por parte dos pais, a preocupação em planejar o futuro dos filhos no negócio. Nesse aspecto em particular, a ação dos irmãos Azevedo merece atenção, uma vez que a literatura registra que a sobrevivência do negócio relaciona-se ao planejamento do futuro dos filhos na empresa e ao êxito do processo sucessório (GERSICK et al., 1997). No Grupo Seculus, a entrada da segunda geração na empresa era, antes de tudo, uma forma de reforçar a unidade familiar e de assegurar a permanência dos negócios na família. Importava mais os filhos assumirem suas responsabilidades e contribuírem para o crescimento dos negócios do que a própria formação como futuros executivos ou gestores do negócio.

REAd I Porto Alegre - Edição 75 - N 2 - maio/agosto 2013 - p. 485-516 
Ciclo de vida, sucessão e processo de governança em uma empresa familiar: um estudo de caso no grupo Seculus

Observou-se forte influência dos pais para que os filhos se integrassem nos negócios, em detrimento de suas vocações individuais. Assim, os relatos dos acionistas e dos membros da segunda geração revelaram uma opção natural pela iniciação profissional nas empresas do grupo. Nesse aspecto, pode-se questionar se a iniciação prematura da segunda geração no trabalho não pode ter comprometido o processo de individualização dos filhos, uma vez que esse processo teve lugar no meio empresarial. Os filhos podem ter se submetido aos valores praticados e disseminados nas empresas, em especial no que se refere à coesão familiar. A expectativa dos pais em relação aos filhos, na medida em que necessitavam de pessoas de confiança no negócio, atuou no sentido de pressioná-los.

Um dos desafios relacionados aos filhos, segundo Gersick et al. (1997), diz respeito às primeiras decisões sobre suas carreiras. Pelos relatos apresentados, não se descarta a possibilidade de que essa escolha tenha partido dos pais e que tenha sido aceita pelos filhos sem contestação. Essa perspectiva encontra respaldo em um contexto familiar marcado pelo consenso, o que pode ter contribuído para inibir eventuais manifestações ou desejos contrários a essa opção. Por outro lado, a inevitabilidade da troca de comando, bem como a sua proximidade, tendo em vista a idade dos fundadores e os limites de prazo impostos pelo Acordo de Acionistas, que confere ao processo sucessório do Grupo Seculus um senso de urgência. Essa preocupação pode ser confirmada pela visão de Casillas, Vázquez e Díaz (2007), Lodi (1987), Bernhoeft (1987), Gersick et al. (1997), os quais garantem que o êxito do processo sucessório depende essencialmente da antecedência com a qual este é planejado e executado. Em outras palavras, a dimensão tempo exerce papel preponderante para que a transferência de poder entre gerações seja bem-sucedida ou se converta, por outro lado, em fracasso. Essa parece ser no momento a principal preocupação dos irmãos Azevedo quanto à transferência de poder entre a primeira e a segunda gerações.

O eixo propriedade caracteriza-se pela posse do controle acionário pelos membros da família. No grupo pesquisado não existem acionistas que não sejam membros da família. Assim, a propriedade está dividida entre os irmãos fundadores, pertencentes à primeira geração, além dos nove filhos do acionista majoritário, que se tornaram acionistas devido ao falecimento de sua mãe.

À época da fundação, a família Azevedo era constituída pelo total de 18 irmãos. A primeira divisão societária, definida em 21 de abril de 1960, data da fundação do grupo, atribuiu a Jairo Azevedo $51 \%$ da participação total. Os $49 \%$ restantes foram divididos igualmente entre sete irmãos, o que resultou num montante de $7 \%$ para cada um. Em 1966, a 
Vera L. Cançado, Juvêncio Braga de Lima, Cristiana Fernandes de Muylder \& Ricardo Brandão Castanheira

evolução dos negócios e o empenho dos irmãos para fazê-lo funcionar trouxeram a demanda pela revisão da participação societária. Artur Azevedo menciona que em uma das reuniões semanais, realizadas aos sábados, os irmãos se posicionaram quanto à necessidade da alteração.

\footnotetext{
Foi colocado à mesa que a matriz societária poderia não dar sustentação à continuidade do futuro dos negócios. Jairo, em princípio, não gostou da nossa proposta. Ficou um pouco chateado. [...] Passados alguns dias, em outra reunião, o Jairo apresentou como solução para aquele tipo de problema uma nova matriz societária.
}

A nova proposta, aceita por todos, estabeleceu que Jairo passaria a deter $30 \%$ da participação total, ficando os outros $70 \%$ divididos igualmente entre os demais sete irmãos. Artur reforça a importância dessa decisão: "Esse arranjo societário foi fundamental para haver equilíbrio e interesse total de todos os sócios”. A partir de então, a sociedade ganhou novo fôlego e a união entre os irmãos renovou-se.

Outras mudanças nesse campo ocorreram em função da saída e entrada de irmãos. Diante da nova alteração, coube a Jairo Azevedo 33\%, sendo que $11 \%$ passaram a ser a parte atribuída a cada um dos demais irmãos fundadores. O restante, $1 \%$, passou para as mãos da irmã Maria José. A situação atual é a mesma de janeiro de 2000, quando um novo arranjo societário se fez necessário, motivado pelo falecimento da primeira esposa de Jairo. Dessa forma, $16,5 \%$ da participação de Jairo foram repassados, em partes iguais, para seus nove filhos.

Entre os membros da segunda geração, caracterizada pelos filhos dos acionistas, oito trabalham na empresa, mas sem participação acionária. São eles: Alexandre, Roberto e Paulo, filhos de Artur Azevedo; Lílian, César, Rodrigo e Ana Carolina, filhos de Márcio Azevedo; e Renato, filho de Élcio Azevedo. Dos filhos de Jairo Azevedo, apenas Ricardo Azevedo atua na empresa, tendo sido designado pelo pai e demais irmãos para representá-los no Conselho de Administração. A partir desses dados, verifica-se o início da evolução para a fase de consórcio de primos.

Com base nessas informações, observa-se que o estágio da sociedade entre irmãos caracterizou o início das atividades e ainda se mantém predominante na estrutura de propriedade do Grupo Seculus até a conclusão desta pesquisa. Para Gersick et al. (1997), essa fase tem como características centrais a divisão acionária e o controle efetivo nas mãos de uma geração de irmãos, o que se confirma no caso em estudo. Como decorrência, o primeiro desafio desse estágio refere-se à definição da participação societária. No Grupo Seculus, a 
Ciclo de vida, sucessão e processo de governança em uma empresa familiar: um estudo de caso no grupo Seculus

concepção da primeira divisão acionária teve como referência o histórico de relacionamento familiar.

Outro desafio da gestão da propriedade refere-se à entrada da terceira geração. Para Gersick et al. (1997), a harmonia existente entre os irmãos tende a se dissipar em meio às ramificações que configuram a geração de primos. Essa perspectiva ainda não foi detectada na história da família Azevedo. O controle acionário e administrativo centralizado na primeira geração de irmãos restringiu o acesso dos membros da segunda geração ao poder. Nesse sentido, a terceira geração, como consequência, permanece afastada dos negócios. Tal fato só se reverterá a partir da transição do estágio de sociedade entre irmãos para o de consórcio de primos, o que poderá ocorrer a partir do momento em que a segunda geração assumir o controle da propriedade e/ou da gestão.

A harmonia predominante entre os irmãos da primeira geração, alicerçada pela forte liderança de Jairo Azevedo, atua como elemento de equilíbrio em meio às diversas ramificações familiares. Entretanto, subjacente a essa harmonia, podem ser evocados potenciais conflitos que apareceram nas entrelinhas dos relatos, principalmente na mudança da matriz societária seis anos após a criação da sociedade de irmãos; nas discussões sobre desbalanceamento de tempo de dedicação à empresa por parte do principal dirigente em relação aos seus sócios e irmãos, conforme aventado pela esposa; nas dúvidas dos herdeiros sobre a escolha de carreiras dos herdeiros; na tentativa do representante do grupo de herdeiros de tratar com o tio sobre a inserção atual e futura da segunda geração no âmbito do grupo empresarial. Também, refletindo sobre os fatos apurados nas narrativas dos entrevistados, percebe-se que conflitos reais possam ter se manifestado no momento da transição de direção, com a atuação da consultoria que conduziu o enxugamento no número de familiares na empresa em geral. Não se tratou, provavelmente, de um simples fato gerencial a passagem de 64 para sete familiares atuando na empresa e a imediata criação de regras de ingresso, convergindo para a situação atual de "porta de entrada muito estreita".

Por outro lado, os conflitos de interesses entre gerações tenderam a ser mitigados ou tamponados, tendo em vista os valores e a união familiar promovidos por Jairo Azevedo, com a aquiescência dos demais irmãos. A forte identificação de Jairo e de seus irmãos com o hábito de trabalhar arduamente para sobreviver, um valor adquirido das gerações anteriores, auxiliou-o a contornar situações potencialmente conflituosas. Soma-se a isso o forte espírito de liderança de Jairo, que, ao longo do tempo, funcionou e ainda funciona como elemento agregador que, ao mesmo tempo em que assegura a sobrevivência do negócio e mantém a 
Vera L. Cançado, Juvêncio Braga de Lima, Cristiana Fernandes de Muylder \& Ricardo Brandão Castanheira

união da família empresária, medeia os conflitos potenciais. Como forma de prevenir a eclosão de tais conflitos, frente à eminente entrada da segunda e terceira gerações nos negócios, o Grupo Seculus vem investindo fortemente na criação de mecanismos de governança.

\section{CICLOS EVOLUTIVOS, DESAFIOS-CHAVE E PRÁTICAS DE GOVERNANÇA}

Focando a governança, a implantação do sistema no Grupo Seculus se deu em 2008. Como primeira medida, criou-se o Conselho de Administração, com a participação de quatro acionistas familiares e três conselheiros profissionais externos. Compõem o conselho os irmãos Artur, Márcio e Élcio Azevedo, além de Ricardo Azevedo, filho de Jairo, que atua como representante do pai e dos seus irmãos acionistas. O principal papel desse conselho é cobrar dos executivos responsáveis pelas empresas as ações e resultados auferidos, tendo como referência o planejamento estratégico das empresas.

Em seguida, criou-se o Conselho de Acionistas, presidido por Jairo Azevedo. Também participam desse conselho os demais irmãos acionistas, além de Ricardo Azevedo. Esse conselho tem como finalidade deliberar sobre os investimentos a serem realizados pelo grupo e suas ações devem estar permanentemente alinhadas às medidas adotadas pelo Conselho de Administração.

Finalmente, criou-se o Conselho de Família, conforme explica Élcio Azevedo: "Nós fizemos um Conselho de Família, composto pela segunda e pela terceira gerações e com a presença de um membro da primeira geração. No caso, sou até eu o escolhido". O objetivo desse conselho, que se reúne semestralmente, é levar aos familiares informações e decisões relativas às empresas do grupo. Funciona como uma forma de estimular os familiares a participarem mais ativamente da vida das empresas, além de contribuir para manter a união da família em torno do grupo.

No entanto, pode-se afirmar que a governança, assim como as demais iniciativas de modernização da gestão, ainda convive com desajustes, tendo em vista, por exemplo, que membros do Conselho de Administração exercem, concomitantemente, os papéis de fiscalizadores dos seus próprios atos, uma vez que permanecem à frente da gestão dos negócios. Márcio Azevedo confirma essa visão ao reconhecer a presença de acionistas em duas esferas distintas da governança:

[...] falta profissionalizar a gestão, porque ainda existe gestor que é acionista e é do Conselho de Administração. Mais a ideia é que saia da gestão. [...] Dentro do

REAd I Porto Alegre - Edição 75 - N² 2 - maio/agosto 2013 - p. 485-516 
Ciclo de vida, sucessão e processo de governança em uma empresa familiar: um estudo de caso no grupo Seculus

Acordo de Acionistas, nós criamos data limite para estar no grupo, e o passo seguinte vai ser a saída do Conselho de Administração das funções de direção.

A governança no Grupo Seculus ainda se encontra em estágio embrionário. Sua implantação foi fundamental para favorecer o início do processo sucessório, viabilizando a profissionalização dos sócios e, em decorrência, dos herdeiros. O modelo de governança implantado no Grupo Seculus adota a mesma configuração proposta por Lank (2003). O autor entende que a governança na empresa familiar fundamenta-se em três órgãos vitais, a saber: o Comitê de Acionistas, o Conselho de Família e o Conselho de Administração. No Grupo Seculus, o Conselho de Administração destaca-se, entre outras funções, pelo acompanhamento e fiscalização dos resultados obtidos pelos executivos do grupo, entre os quais se encontram membros da segunda geração. Essa perspectiva equipara-se à visão de Vidigal (1996), para quem o Conselho de Administração zela para que os diretores ajam em consonância com o interesse dos acionistas. Pode-se concluir que a criação da governança no Grupo Seculus permitirá aos sócios fundadores instalarem-se em uma nova instância de poder, o que pode funcionar como lenitivo para o inevitável momento da passagem de bastão para a geração mais nova. Tal fato os manterá ligados ao negócio, embora as atribuições de conselheiro os afastem da gestão do dia-a-dia.

A particularidade do caso Seculus em relação ao desenvolvimento da família é que se pode afirmar que, após a criação da empresa, irmãos ainda solteiros iriam criar suas famílias. A rigor, pode-se falar em famílias proprietárias. A expressão "passagem do bastão" ocorre entre irmãos fundadores. No mesmo sentido, quando se observa o eixo da propriedade, o estágio de desenvolvimento, apesar de ser uma empresa de longa existência, ainda permanece quase como uma sociedade entre irmãos, apenas registrando-se entre os proprietários, com pequena quantidade relativa de ações, alguns filhos de um dos irmãos, cuja esposa faleceu.

Quanto ao estágio de desenvolvimento da empresa, pode-se afirmar que se trata de uma expansão/formalização. Houve acentuado desenvolvimento da empresa original, criação de várias outras empresas de propriedade dos fundadores, com consequente criação de uma holding controladora do grupo, que passou a denominar-se Grupo Seculus. Nessa fase, dois aspectos merecem ser destacados: o planejamento estratégico e a profissionalização. O planejamento estratégico já faz parte das atividades e a profissionalização ainda se encontra em processo. Cabe mencionar que, nesse caso específico, o que deveria ser um processo de profissionalização que pudesse pôr em cheque a relação fundador-dirigente e seus filhos herdeiros ainda envolve a opção entre fundadores e seus filhos ou profissionais oriundos do 
Vera L. Cançado, Juvêncio Braga de Lima, Cristiana Fernandes de Muylder \& Ricardo Brandão Castanheira

mercado. Na verdade, constata-se que filhos de alguns fundadores já atuam em funções de direção. Mas a problemática da profissionalização é considerada em sentido amplo, sendo considerada tanto por Jairo como por Élcio como um processo ainda em implantação e lento.

Verifica-se, pois, que a prática da governança em empresas familiares reúne particularidades próprias. Trata-se de uma proposta de intervenção associada às exigências de stakeholders, mas ao mesmo tempo envolve a reunião de elementos essenciais para a compreensão dos desafios enfrentados. São desafios que requerem criatividade e interação social de shareholders e stakeholders e destes entre si mesmos (ASTRACHAN et al., 2006; CORBETTA; MINICHILLI, 2006). No caso estudado, a intervenção de consultores levou à instalação de estruturas de governança, ao Comitê de Acionistas e Conselho de Família, que passaram a atuar regularmente em paralelo às ações do Conselho de Administração. Assim, a prática da governança representa uma forma de criação de condições para encaminhamento dos desafios estratégicos identificados pela abordagem de uma dada empresa familiar por meio do modelo. Evidentemente, e esse caso estudado comprova, a prática da governança sistematizada representa uma oportunidade para equacionamento de outros desafios para o desenvolvimento de uma dada empresa familiar.

Do ponto de vista teórico, torna-se clara a complementaridade entre o modelo de Gersick et al. (1997) e as concepções sobre a governança. Enquanto pela abordagem do modelo dos três eixos do desenvolvimento da empresa familiar são expostos os desafios estratégicos, os modelos da governança buscam explicar as condições para que esses desafios estratégicos sejam equacionados.

Com efeito, não tivessem sido implantados o Comitê de Acionistas, o Conselho de Família e o Conselho de Administração, os problemas já existentes, que constituem novos desafios no processo sucessório, continuariam a representar desafios para a empresa e para a compreensão daquela organização como estudo de caso. A prática da governança em empresas familiares redistribui, de modo sincrônico, aspectos problemáticos que atravessam a vida de uma empresa familiar. De modo particular, representa um caminho para equacionar os conflitos reais e potenciais vinculados à sucessão, sobretudo com respeito à da profissionalização.

Os conflitos vinculados à profissionalização estão presentes em mais de uma forma em empresas familiares. No caso investigado, manifestou-se inicialmente na avaliação feita pela ação de consultores sobre o quadro profissional da empresa em geral. Apesar de seu crescimento e desenvolvimento, a empresa caminhava para certa dispersão de quadros 
Ciclo de vida, sucessão e processo de governança em uma empresa familiar: um estudo de caso no grupo Seculus

gerenciais em diversos níveis, com a presença, sem critérios, de membros da família em diferentes posições.

A instalação da nova estrutura de governança, com Comitê de Acionistas, Conselho de Família e Conselho de Administração, permite reflexão e encaminhamento de conflitos que estiveram invisíveis ou que surgem a partir da instalação dessas estruturas. Esses conflitos são também marcados pela instância da profissionalização de maneira ampla, pois estão vinculados à confiança quanto à competência de sucessores e quanto à legitimidade da participação de diferentes atores em instâncias decisórias. Torna-se claro, portanto, que a condução da sucessão em empresas familiares envolve desafios relativos ao desenvolvimento de famílias, da empresa e da propriedade. Tais desafios são bem encaminhados quando passam pela criação de estruturas que permitam à família proprietária participar das soluções, equacionadas por práticas de governança.

\section{CONSIDERAÇÕES FINAIS}

Neste estudo foi exposta a história do Grupo Seculus na perspectiva dos ciclos de vida de empresas familiares, tendo como referência o modelo tridimensional de desenvolvimento de Gersick et al. (1997). Ao longo da narrativa e das análises empreendidas, tornou-se clara a expressão de desafios estratégicos vivenciados pelos membros da família e pela empresa, verificando-se que a problemática da sucessão perpassa as várias fases da empresa. Assim, a utilização do modelo permitiu a compreensão dessas dimensões.

Por outro lado, a aplicação desse modelo nesta pesquisa suscita algumas questões. Devido à sua lógica objetiva, o modelo oferece pouco espaço para a análise de variáveis concernentes à interação entre familiares. Nesse sentido, acaba por ocultar aspectos fundamentais para o pleno entendimento da dinâmica familiar. Questões como o processo de amadurecimento dos filhos, transferência de poder entre gerações, contraposição de interesses familiares e empresariais e conflitos extrapolam as necessidades empresariais e se inserem na dimensão humana do relacionamento. No modelo em estudo, tais aspectos são analisados a partir de uma ótica racional e quase didática. À proporção que os dados foram coletados e analisados por meio de tal modelo, questões relativas à subjetividade, que são essenciais para o entendimento da dinâmica entre os três subsistemas, abrigados sob a perspectiva dos três eixos de desenvolvimento da empresa familiar, não emergiram claramente nas entrevistas, empobrecendo, de certo modo, a análise desses dados, principalmente em relação às variáveis 
Vera L. Cançado, Juvêncio Braga de Lima, Cristiana Fernandes de Muylder \& Ricardo Brandão Castanheira

poder e conflitos na empresa familiar. Apesar da opção, de partida, pelo modelo teórico de Gersick et al. (1997), no qual tais questões não são objeto de análise, limitando-se à visão crítica sobre os três sistemas constituintes da empresas familiares, foi possível, entretanto, captar, ainda que de forma indireta, eventuais e potenciais conflitos ao longo da história do Grupo Seculus. Tais aspectos subjacentes aos dados coletados sugerem a utilização do modelo com mais flexibilidade, visando focar as questões de poder e conflitos, dimensões essenciais para o entendimento da dinâmica de empresas familiares.

A configuração do eixo família, notadamente no estágio "passagem de bastão", não traz evidências sobre a transferência de poder para profissionais não familiares, uma vez que assume a sucessão familiar como a única possível. Nesse sentido, sugere-se a inclusão do tema profissionalização como uma variável a ser analisada na estrutura do modelo tridimensional, já que uma geração de sucessores despreparada pode levar a empresa familiar a optar por transferir o poder para profissionais não pertencentes à família.

Cabe ressaltar, ainda, a ausência da governança como elemento de articulação entre os eixos propostos pelo modelo tridimensional. A análise realizada neste trabalho revela que o modelo em estudo trata os três subsistemas - família, propriedade e gestão - de forma estanque, oferecendo pouca interação entre eles. A governança atuaria como uma instância superior e reguladora, propondo-se a delimitar e equilibrar as funções e interesses familiares e empresariais, por meio da atuação do Conselho de Administração, do Conselho de Família e do Conselho de Acionistas. Apesar de se confundir com exigências legais e setoriais, a governança representa um fenômeno passível de interpretações e associações com outros fenômenos associados à dinâmica de empresas familiares. Os desafios estratégicos expostos no modelo de Gersick et al. ( 1997) não se restringem às estratégias como ações no campo dos negócios. São desafios que requerem criatividade e interação social de shareholders $e$ stakeholders e destes entre si. A criação de estruturas de governança não se restringe aos seus elementos formais, tais como os conselhos criados no âmbito do Grupo Seculus. Tornou-se evidente que revelou aspectos processuais, tais como conflitos reais e potenciais, questionamentos entre membros das famílias proprietárias que passaram a fazer parte da consideração de decisões sobre os rumos presentes e futuros da organização.

Este artigo traz, portanto, a exposição de uma situação de criação de estruturas de governança em uma empresa familiar, na qual desafios do processo de sucessão se manifestaram em algumas situações. Apesar da sua vertente de técnica e prática, a governança traz à tona os desafios de empresas familiares, sob uma ótica ampliada, permitindo agregar 
Ciclo de vida, sucessão e processo de governança em uma empresa familiar: um estudo de caso no grupo Seculus

conhecimentos aos produzidos pela abordagem do modelo dos três eixos do desenvolvimento da empresa familiar.

\section{REFERÊNCIAS}

AMENDOLARA, L. A sucessão na empresa familiar. São Paulo: Lazuli, 2005.

ASTRACHAN, J.H.; KLEIN, S.B.; SMYRNIOS, K.S. The F-PEC scale of family influence: a proposal for solving the family business definition problem. In: POUTZIRIOURIS, P.Z.; SMYRNIOS, K.X.; KLEIN, S.B. (ed.). Handbook of research on family business. Cheltenham/UK - Northampton, MA/USA: Edward Elgar, 2006, p. 167-179.

ASTRACHAN, J.H.; KEYIT, H; LANE, S.; McMILLAN, K. Generic model for family business boards. In: POUTZIRIOURIS, P.Z.; SMYRNIOS, K.X.; KLEIN, S.B. (ed.). Handbook of research on family Business. Cheltenham/UK - Northampton, MA/USA: Edward Elgar, 2006. p.317-341.

BARNES, L.; HERSHON, S. Transferring power in the family business. Family Business Review, v. 7, n. 4, p. 377-392, 1994.

BARRY, B. The development of organization structure in the family firms. Journal of General Management, v. 3, n. 1, 1975.

BERNHOEFT, R. Empresa familiar: sucessão profissionalizada ou sobrevivência comprometida. São Paulo: Ibecon, 1987.

BERNHOEFT, R.; GALLO, M. Governança na empresa familiar. Rio de Janeiro: Campus, 2003.

BORGES, A. F., LESCURA, C., OLIVEIRA, J. L. de. Empresas familiares: mapeamento da produção científica brasileira no período 1997-2009. In: ENEO, VI, 2010, Florianópolis. Anais eletrônicos, Florianopolis: ANPAD, 2010. ENEO 386.

BROCHAUS, R.H. Family business succession: suggestions for future research. Family Business Review, v. 17, n. 2, p. 165-177, 2004.

CASILLAS, J. C.; VÁZQUEZ, A.; DÍAZ, C. Gestão da empresa familiar: conceitos, casos e soluções. São Paulo: Thomson, 2007.

REAd I Porto Alegre - Edição 75 - Nº 2 - maio/agosto 2013 - p. 485-516 
Vera L. Cançado, Juvêncio Braga de Lima, Cristiana Fernandes de Muylder \& Ricardo Brandão Castanheira

CHUA, J.H.; CHRISMAN, J.J.; SHARMA, P. Defining the family business by behavior. Entreperneurship theory and practice, v. 23, n. 4, p. 19-39, 1999.

COHN, M. Passando a tocha: como conduzir e resolver os problemas de sucessão familiar. São Paulo: Makron, McGraw-Hill, 1991.

COLLIS, J.; HUSSEY, R. Pesquisa em Administração: um guia prático para alunos de graduação e pós-graduação. 2. ed. Porto Alegre: Bookman, 2005.

CORBETTA, G; MINICHILLI, A. Board of directors in Italian public family-controlled companies. In: POUTZIRIOURIS, P.Z.; SMYRNIOS, K.X.; KLEIN, S.B. (ed.). Handbook of research on family business. Cheltenham/UK - Northampton, MA/USA: Edward Elgar, 2006, p. 488-500.

COSTA, R.T. Importância dos conselhos na governança corporativa. In: ÁLVARES, E.; Governando a empresa familiar. Rio de Janeiro: Qualitymark; Belo Horizonte: Fundação Dom Cabral, 2003.

DANES, S.; RUETER, M. A.; KWON, H. K.; DOHERTY, W. Family FIRO model: an application to family business. Family Business Review, v. 15, n. 1, p. 31-45, 2002.

DAVEL, E.; SILVA, J.C.S.; FISCHER, T. Desenvolvimento tridimensional das organizações familiares: avanços e desafios teóricos a partir de um estudo de caso. Salvador: Organização \& Sociedade, v. 7, n. 18, p. 99-116, maio/ago 2000.

DAVIS, P.S.; HAVERSTON, P.D. The influence of family on business succession process: a multigenerational perspective. Entrepreneurship theory and practice, v. 22, n. 3, p. 31-53, 1998.

DONNELLEY, R.G. The family business. Harvard Business Review, v. 42, n. 4, p. 93-105, Jul./Aug.1964.

DYER JR., W.G. Cultural change in family firms: anticipating and managing business and family transitions. San Francisco: Jossey Bass, 1986.

GERSICK, K.E.; DAVIS, J. A.; HAMPTON, M. M.; LANSBERG, I. De geração para geração: ciclo de vida da empresa familiar. São Paulo: Negócio, 1997. 
Ciclo de vida, sucessão e processo de governança em uma empresa familiar: um estudo de caso no grupo Seculus

GIL, Antonio. C. Métodos e técnicas de pesquisa social. 5.ed. São Paulo: Atlas, 2007.

GRZESZCZESZYN, G.; MACHADO, H.V. Empresas familiares do setor moveleiro e desenvolvimento local em Guarapuava-PR. Salvador: Organização \& Sociedade, v. 16, n. 51, p. 749-769, out/dez, 2009.

GRZYBOVSKI, D. Plataforma de conhecimentos e aprendizagem transgeracional em empresas familiares. 2007. 383p. Tese (Doutorado em Administração), Universidade Federal de Lavras, Lavras, 2007.

GRZYBOVSKI, D.; LIMA, J.B. O conceito de família e o dilema metodológico nos estudos sobre empresas familiares. In: ENEO, III, 2004, Atibaia/SP. Anais eletrônicos, Atibaia/SP: ANPAD, 2004 (ENEO 392).

HANDLER, W.C. Succession in family firms: a mutual role adjustment between entrepreneur and next-generation family members. Entrepreneurship theory and practice, v. 15, n. 1, p. 37 $51,1990$.

HANDLER, W.C. Succession experience of the next generation. Family Business Review, v. 5, n. 3, p. 283-307, 1992.

HOY, F.; SHARMA P. Navigating the family business education maze. In: POUTZIRIOURIS, P.Z., SMYRNIOS, K.X.; KLEIN, S.B. (ed.). Handbook of research on family business. Cheltenham/UK - Northampton, MA/USA: Edward Elgar, 2006, p. 11-24.

LANK, A.G. Sucessão na gestão: desafio chave. In: ÁLVARES, E. Governando a empresa familiar. Rio de Janeiro: Qualitymark; Belo Horizonte: Fundação Dom Cabral, 2003.

LANZANA, A.; CONSTANZI, R. As empresas familiares brasileiras diante do atual panorama econômico mundial. In: MARTINS, I.G.S.; MENEZES, P.L.; BERNHOEFT, R. Empresas familiares brasileiras: perfil e perspectivas. São Paulo: Negócio, 1999.

LEONE, N.C.P.G. Sucessão na empresa familiar. São Paulo: Atlas, 2005.

LETHBRIDGE, T. O desafio de trabalhar com o pai. Exame, São Paulo, n. 5, p. 22-34, mar. 2005 . 
Vera L. Cançado, Juvêncio Braga de Lima, Cristiana Fernandes de Muylder \& Ricardo Brandão Castanheira

LODI, J.B. A empresa familiar. São Paulo: Pioneira, 1998.

LODI, J.B. Sucessão e conflito na empresa familiar. São Paulo: Pioneira, 1987.

McGUIRVEN, C. The dynamics of management sucession: a model of chief executive succession in the small family firm. Family Business Review, v. 4, n. 2, 1989.

NORDVQUIST, M.; MELIN, L. The dynamics of family firms: an institutional perspective on corporate governance and strategic change. In: FLETCHER, D. (ed). Understanding the small family business. London/New York: Routledge, 2002, p. 94-110.

OLIVEIRA, D.P.R. Empresa familiar: como fortalecer o empreendimento e otimizar o processo sucessório. São Paulo: Atlas, 1999.

PAIVA, K.C.M.; OLIVEIRA, M.C.S.M.; MELO, M.C.O.L. Produção científica brasileira sobre empresa familiar: um metaestudo de artigos publicados em anais de eventos da ANPAD no período de 1997-2007. RAM - Revista de Administração Mackenzie, v. 9, n. 6, p. 148-173, 2008.

RICCA, D. Sucessão na empresa familiar: conflitos e soluções. São Paulo: CLA, 2007.

SANDIE, A.G.; LABADIE, G.S.; SARIS, W.; MAYORDOMO, X. M. Internal factors of family business performance: an integrated theoretical model. In: POUTZIRIOURIS, P.Z.;

SMYRNIOS, K.X.; KLEIN, S.B. (ed.). Handbook of research on family business. Cheltenham/UK - Northampton, MA/USA: Edward Elgar, 2006. p. 145-166.

SILVA, J.C.S.; FISCHER, T.; DAVEL, E. Organizações familiares e tipologias de análise: o caso da organização Odebrecht. In: ENANPAD, 1999. Foz do Iguaçu. Anais... Foz do Iguaçu: ANPAD, 1999.

SILVA JR., A.; MUNIZ, R.M. Sucessão, poder e confiança: um estudo de caso em uma empresa familiar capixaba. RAUSP, São Paulo, v.41, n.1, p.107-117, jan/fev/mar 2006.

SUEHIRO, A.; WAILERDSAK, N. Family business in Thailand: Management, Governance and Future Challenges. ASEAN Economic Bulletin, v. 21, n. 1, p. 81-93, Apr. 2004.

TAGIURI, R.; DAVIS, J. Bivalent attributes of the family firms. Family Business Review, v. 9, n. 2, 1996. 
Ciclo de vida, sucessão e processo de governança em uma empresa familiar: um estudo de caso no grupo Seculus

UHLANER, L.M. Business family as a team: underlying force for sustained competitive advantage. In: POUTZIRIOURIS, P.Z.; SMYRNIOS, K.X.; KLEIN, S.B. (ed.). Handbook of research on family business. Cheltenham/UK - Northampton, MA/USA: Edward Elgar, 2006, p. 167-179.

VIDIGAL, A.C. Viva a empresa familiar! Rio de Janeiro: Rocco, 1996.

WARD, J.L. Perpetuation the family business. 50 lessons learned from long-lasting, successful families in business. New York: Palgrave Macmillan, 2004.

WARD, J.L. The special role of strategic planning for family business. Family Business Review, v. 1, n. 2, 1998, p. 105-117.

YIN, R.K. Estudo de caso: planejamento e métodos. Porto Alegre: Bookman, 2005.

' Os autores gostariam de agradecer o apoio da Fundação de Amparo à Pesquisa do Estado de Minas Gerais - FAPEMIG. 